Postprint of Acta Hortic. 1156, 777-780. The original publication is available at:

https://doi.org/10.17660/ActaHortic.2017.1156.114

\title{
Strawberry cultivar and breeding lines susceptibility to Phytophthora crown and root rot in Huelva (Spain)
}

\author{
C. Borrero ${ }^{1}$, A. Refoyo ${ }^{2}$, C. Sanz ${ }^{3}$ and M. Avilés ${ }^{1}$ \\ 1E.T.S.I.A. Universidad de Sevilla, Sevilla, Spain, ${ }^{2}$ Fresas Nuevos Materiales S.A, Huelva, \\ Spain,. ${ }^{3}$ Instituto de la Grasa, CSIC, Sevilla, Spain.
}

\begin{abstract}
Phytophthora crown and root rot of strawberries is caused by Phytophthora cactorum. Breeding programs for resistance to this disease are in progress in Spain. In a previous work, the different susceptibility of the most important strawberry cultivars used in Huelva (Spain) was observed. In the present work, 2 cultivars and 3 breeding lines were included in assays of susceptibility with artificial inoculation. Eighteen plants of each cultivar were inoculated with a root bath in a suspension with $P$. cactorum propagules. After inoculation, plants were cultivated in a growth chamber in a randomized design with three repetitions of six plants each. The assays were conducted two times from September to December in 2014 and 2015.

Results showed 4 susceptibility groups: 'Fortuna' the most susceptible cultivar; 'Primoris' with moderate susceptibility; 'A11-407P-3' and 'A10-48-3' with lower susceptibility and 'A10-207P'-8 the lowest susceptible breeding line. 'A10-207P-8' had $56.4 \%$ less disease severity than the most susceptible cultivar. Therefore, the use of these three breeding lines will be an interesting resource to control this disease in an integrated disease management program.
\end{abstract}

Keywords: Breeding, Fragaria $\times$ ananassa, soilborne, disease, Phytophthora cactorum.

\section{INTRODUCTION}

Crown and root rot caused in strawberry (Fragaria $\times$ ananassa Duch.) caused by Phytophthora cactorum was first reported in northern Germany in 1952 (Deutschmann, 1954). Since then, this disease has become a common problem in strawberry areas over the world (Semüller, 1984; Martínez et al., 2010). Spain is one of the five top strawberry producers in the world. In 2013 strawberry yield reached at 312,500 t (FAO, 2016). This culture is mainly localized in Huelva coast. Phytophthora crown and root rot of strawberries in Huelva, as other soil fungal diseases, is becoming worse every year during the phase-out of methyl bromide (Miranda et al., 2012) because fumigants authorized for soil to control disease are less effective. In this context, non-chemical approaches must be considered and developed. The use of strawberry plants resistant or tolerant against this and other soilborne pathogens, as a part of integrated control strategies, is a realistic alternative that must be seriously taken into account. Breeding programs towards resistance against important soilborne diseases are in progress in different countries (Faedi et al., 2002) including Spain. 
This work summarized the study to characterize the response of some strawberry cultivars used in Huelva and new advanced selections into the Breeding program developed by Fresas Nuevos Materiales S. A. in collaboration with the University of Seville.

\section{MATERIALS AND METHODS}

\section{Inoculation Methods}

Five isolates obtained from affected plants in Huelva (Spain) were selected for inoculation. Isolate selection was different for each year in order to use fresh isolates. Inoculum was obtained blending 7 days-V8 growing colonies from that isolates in $100 \mathrm{ml}$ of sterilized water per plate. Root plants were submerged in this suspension during one hour with orbital agitation $125 \mathrm{rpm}$. After that, $200 \mathrm{ml}$ of this suspension was poured per pot with six plants. Plants were incubated at $100 \%$ humidity during two weeks.

\section{Susceptibility Assay}

This assay included 2 cultivars ('Fortuna' and 'Primoris') and 3 breeding lines (A1084-3A10-207P-8 and A11-407P-3). Strawberry runner plants growing in 1.5 litres pots with peat growth medium were used for assay. Plants were cultivated in a growth chamber at 25 ${ }^{\circ} \mathrm{C}$ during the day and $24{ }^{\circ} \mathrm{C}$ at night (photoperiod: $10 \mathrm{~h}$ day and $14 \mathrm{~h}$ night) with a randomised complete block design with three repetitions (pots). The assays were conducted two times from September to December in 2014 and 2015.

\section{Severity Assessment}

Disease severity was monitored once per week after inoculation and was scored based on a symptom severity scale where: $0=$ asymptomatic plants; $1=$ infected plants (necrotic leaves); 2 = dead plants. Disease severity was expressed as proportion of the maximum possible disease severity. The area-under-the-disease-progress-curve-standardized (AUDPCs) per plant was calculated by disease severity integrated between symptoms onset and bioassay final time and dividing by the total epidemic time (days).

\section{Statistical Analysis}

Data collected from the trials were analyzed with Statgraphics Plus, Version 6 (SGS, 1999). Cultivars and year effect on severity (AUDPCs) were analyzed with a factorial ANOVA. Significant means were compared by Fisher LSD test $(P<0.05)$.

\section{RESULTS AND DISCUSSION}

Cultivars showed different susceptibility to P. cactorum $(P<0.001)$. Year factor also had significant differences. Severity was higher in 2014 than in $2015(P<0.001$, data not shown). On the contrary, the interaction between cultivar and year did not showed significant difference $(P>0.05$, data not shown). The different severity in both years can be due to the variable virulence for each group of isolates per year. Phytophthora isolates storage can induce the loss of virulence (Shaw, 1988). On the other hand, physiological condition of the host also greatly affects susceptibility, which can fluctuate considerably throughout the year (Duncan, 2002). Therefore, the different severity between years can be explained for virulence attenuation after isolates storage or for variations in plant development at the beginning of assays.

Results showed 4 susceptibility groups: 'Fortuna' the most susceptible cultivar; 'Primoris' with moderate susceptibility; 'A11-407P-3' and 'A10-48-3' with similar susceptibility than 'Primoris' and 'A10-207P-8' and finally 'A10-207P-8' had lower susceptibility than 'Primoris'. 'A10-207P-8' had 56.4\% less disease severity than the most susceptible cultivar (Fig. 1). The high susceptibility in 'Fortuna' cultivar to crown root rot 
recorded in these bioassays is confirmed with the high crown root rot incidence in 'Fortuna' plants in Huelva fields as observed by farmers and technicians. This cultivar is the most cultivated in the last two years (Gómez-Mora et al., 2015). Therefore, the use of these three breeding lines will be an interesting resource to control this disease in an integrated disease management program.

\section{ACKNOWLEDGEMENTS}

This research was supported by grants from Corporación Tecnológica de Andalucía (CTA: 12/633). We thank S. Castillo, A. Gata and S. Pérez for excellent technical assistance.

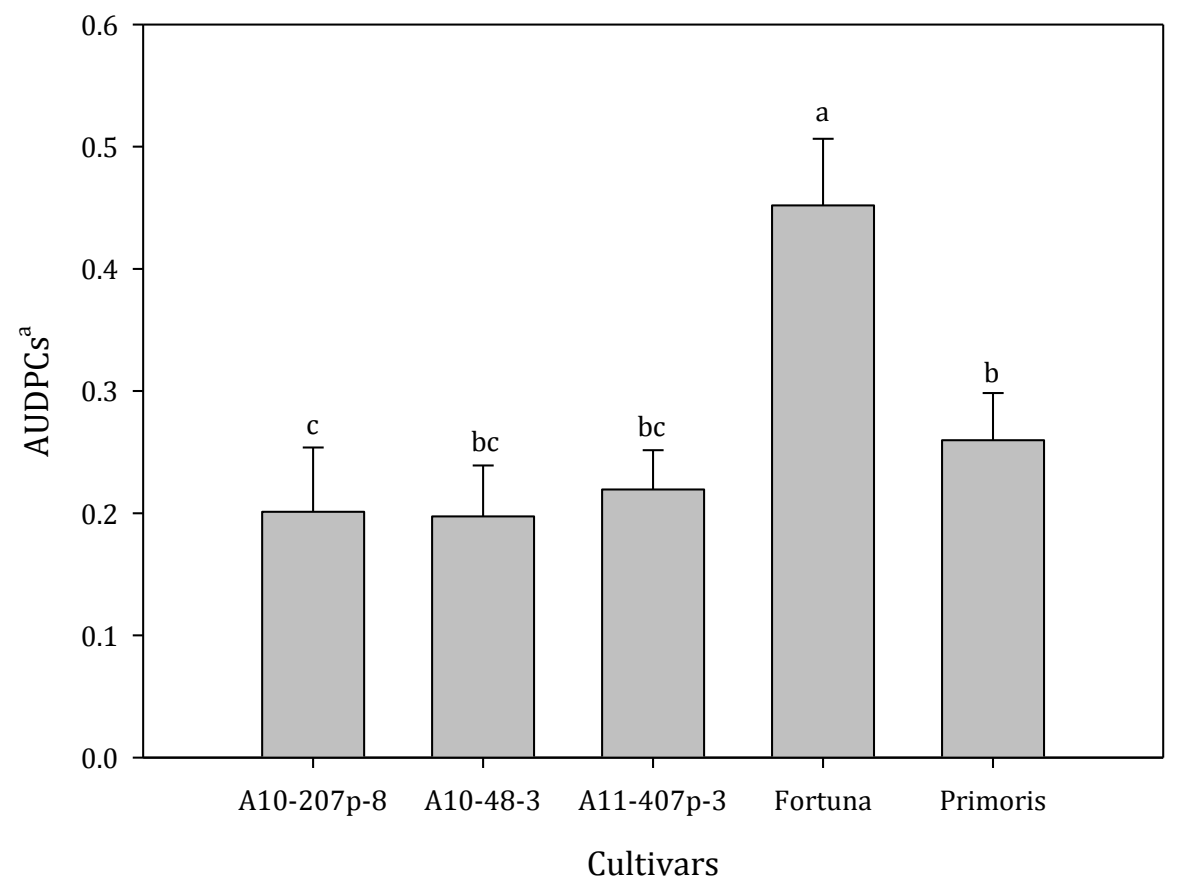

Figure 1: Disease severity recorded during the bioassays in five cultivars.

aAUDPCs: Area-under-the-disease-progress-curve-standardize per plant was calculated by disease severity integrated between symptoms onset and bioassay final time and dividing by the total epidemic time (days). Data were recorded from two bioassays performed in two different years.

Analysis of variance was performed with transformed data with $\mathrm{x}^{-1 / 2}$. Bars with the same letters were not significantly different according to LSD test at $P<0.05$. Standard error of mean is indicated by a vertical line $(n=6)$.

\section{Literature cited}

Deutschman, F. (1954). Eine Wurzelfäule and Erdbeeren, hervorgerufen durch Phytophthora cactorum (Leb. et Cohn) Schroet. Nachrichtenblatt des Deutschen Pflanzenschutzdienstes 6, 7-9.

Duncan, J.M. (2002). Prospects for integrated control of Phytophthora diseases of strawberry. Acta Hort. 567, 603-611. http://dx.doi.org/10.17660/ActaHortic.2002. 567.130 
Faedi, W., Mourgues, F., and Rosati, C. (2002). Strawberry breeding and varieties: situation and perspectives. Acta Hort. 567, 51-59. http://dx.doi.org/10.17660/ActaHortic.2002. 567.1 .

FAO. (2016). http://faostat.fao.org.

Gómez-Mora, J.A., Miranda, L., Medina, J.J., Soria, C. and Domínguez, P. (2015). Informe Técnico "Panorama varietal en el cultivo de la fresa en Huelva. Periodo 2012-2015". Ed. Consejería de Agricultura, Pesca y Desarrollo Rural, Instituto de Investigación y Formación Agraria y Pesquera.

Martínez, F., Castillo, S, Carmona, E and Avilés, M. (2010). Disemination of Phytophthora cactorum, cause of crown rot in strawberry, in open and closed soilless growing systems and the potential for control using slow sand filtration. Sci. Hort. 125, 756-760. http:// dx.doi.org/10.1016/j.scienta.2010.05.010.

Miranda, L., Domínguez, P., Soria, C., Talavera, M., Chamorro, M., Romero, F., De los Santos, B., Medina-Mínguez, J.J. and López-Aranda, J.M. (2012). Nuevos resultados en la evaluación de desinfestantes de suelos para el cultivo de la fresa. Agrícola Vergel 353, 7-13.

Seemüller, E. (1984). Crown rot (vascular collapse). In: Compendium of Strawberry Diseases. J.L. Maas, ed. (St Paul MN, USA: APS Press), p. 83-85.

Shaw, D.S. (1966). The Phytophthora Species. In: Advances in Plant Pathology, Vol. 6: Genetics of Plant Pathogenic Fungi. G.S. Sidhu, ed. (London, Academic Press), p. 27-51. 